\title{
Cover Memo: Volume 19, Issue 1 Celebrating a Decade of Publishing Innovative Policy Solutions Designed by the Next Generation
}

\author{
Rosie Dutt
}

Editor-in-Chief, Journal of Science Policy \& Governance

\section{Adriana Bankston}

CEO \& Managing Publisher, Journal of Science Policy \& Governance

https://doi.org/10.38126/JSPG1901CM

This Standard Issue of the Journal of Science Policy \& Governance (JSPG) celebrates 10 years since the journal's first published standard issue in 2011.

We are delighted to introduce the 19th Volume of the Journal of Science Policy \& Governance (ISPG), which is focused on evergreen policy topics that necessitate innovative and bold solutions designed by the next generation for a better future. This is a critical time in our society when evidence-based policymaking is more important than ever before, and when additional knowledge and novel perspectives are required to tackle societal problems that may have been unprecedented 10 years ago.

This new volume is focused on a few broad themes in science policy, including environmental, health and research policies, which require actions at all levels of government, in addition to the involvement of citizens in the policymaking process. Some of these same policy topics were discussed in the first JSPG published standard issue in 2011, highlighting the need for the next generation to design novel solutions to these problems in a manner that is adaptable to current societal needs.

Additionally, JSPG is more than just a journal. We provide an independent platform for the next generation of science policy leaders, elevate the voices of young scholars in the science and technology policy debate, and contribute to the professional growth of authors by helping them write for a diverse set of audiences, gain credibility in science policy, and leverage their writing for policy engagement.

As such, to commemorate the 10 year anniversary of the first published standard issue in June 2011, authors from that issue described ways in which $J S P G$ has been critical to their career trajectories in science policy, both through publishing and other opportunities for professional development. Former and current editorial leadership also expressed their appreciation for how JSPG helped them gain valuable experience and knowledge in science policy, and provided a stepping stone into the field, often guiding their next career steps.

At the same time, today's society is much different than it was 10 years ago, with increased complexities and a higher level of interconnectedness at an international level. In order to tackle important challenges in our society, it behooves us today to continue challenging the way we think, act, work and collaborate to design a better global future, driven by policy ideas from the next generation.

The welcome statement from the first published standard issue stated the purpose of the journal as: "A publication dedicated toward identifying emerging challenges and exploring novel solutions. All of the articles are authored by students and young scholars, who provide a unique and often undervalued voice in policy 
debates." And while today's society looks much different, our core mission remains the same. As we look ahead at the next decade of publishing, JSPG remains committed to developing the science policy leaders of tomorrow who can leverage their research and writing skills to impact society with their work published in the journal.

Governing Board Member and former JSPG Editor-in-Chief Lida Beninson highlighted the role of the journal to build a community of highly engaged international science policy scholars and advocates now and into the future. We encourage you to contribute to the growth and advancement of this community, and to bring your innovative ideas to the table in shaping the future of science policy.

We look forward to celebrating the next decade of publishing with this growing community of innovators and thinkers in science policy, and to continuing to empower future generations to leverage their publications and ideas into action to tackle emerging societal challenges. We congratulate the authors published in this volume and look ahead to the implementation of their policy solutions towards designing a better future for all.

Rosie Dutt, Editor-in-Chief, Journal of Science Policy \& Governance

Adriana Bankston, CEO \& Managing Publisher, Journal of Science Policy \& Governance

\section{Perspective from $J S P G$ leadership}

To help frame this issue and provide historical context, we asked Shalin Jyotishi, who has been with the journal since 2013 and served as CEO from 2017-2021, to provide his perspective. During his tenure with $J S P G$, Shalin built up the journal as a highly visible and valuable resource to the next generation to publish and elevate their policy ideas.

"When JSPG was first established, the national and international "ecosystem" supporting the involvement of students and early career researchers in science and technology policy was far more nascent. I couldn't be more delighted to join JSPG in celebrating its 19th volume released ten years after the organization's first publication in June 2011. It's been fantastic to support the growth of the field and movement alongside our many partners across the United States and beyond. Serving JSPG as CEO has been one of my greatest professional privileges, and I'm excited to support the next era of the journal. We hear each and every day the tangible impact the journal is having on early career researchers and on the policy landscape. I congratulate current CEO Adriana Bankston, editors, the entire staff - current and former - and the Governing and Advisory Boards on ten years of substantive elevation of early career voices in science and technology policy. Onward." -- Shalin Jyotishi, Senior Analyst, New America; JSPG Senior Advisor and Immediate Past CEO \& Managing Publisher.

Rosie Dutt in her role as Editor-in-Chief for JSPG, leads the Editorial Board and the end-to-end editorial process. By day, Rosie is a $\mathrm{PhD}$ candidate studying the impact of life events on depression and investigating whether brain biomarkers exist within resting-state functional MRI. Prior to her doctoral studies, Rosie has completed a research masters in Bioimaging Science at Imperial College London, a taught masters in Cognitive Neuroscience at Durham University and majored in Psychology, Psychiatry \& Neuroscience at St Georges Medical School, University of London. Rosie has a passion for communicating science and alongside serving as the Editor-in-Chief for $J S P G$, she leads the Editorial Team at 500 Women Scientist and instructs various courses at a University level. Connect with Rosie on Twitter at @DuttRosie.

Adriana Bankston in her role as CEO \& Managing Publisher for JSPG, empowers and activates the world's next generation of science and technology policy decision-makers through substantive, thoughtful, and relevant research, writing, and engagement. She oversees all aspects of JSPG in partnership with the Governing Board, and focuses on strategic partnership development and external relations, overall journal leadership and staff supervision, as well as operations and fundraising. By day, Adriana is a Principal 
Legislative Analyst at the University of California (UC) Office of Federal Governmental Relations in Washington, DC. In addition to working at UC, Adriana is a Biomedical Workforce \& Policy Research Investigator at the STEM Advocacy Institute (SAi), co-chair of the Education Taskforce with Women in Government Relations (WGR), and member of the Engaging Scientists and Engineers in Policy (ESEP) Coalition Steering Committee. Adriana earned her Ph.D. in Biochemistry, Cell and Developmental Biology from Emory University. Connect with Adriana on Twitter at @AdrianaBankston.

Shalin Jyotishi in his role as Senior Advisor to JSPG, provides guidance on strategic outreach, engagement and partnership development for the journal. By day, Shalin is a Senior Analyst on Education and Labor at New America, the United States' leading think-tank, intellectual venture capital fund, and media platform dedicated to renewing the American promise. He is also a visiting scholar at the American Association for the Advancement of Science (AAAS), where he is co-authoring the second edition of Beyond Sputnik: U.S. Science Policy in the 21st Century. Shalin is a World Economic Forum Global Shaper and a fellow in AI. Before joining New America, Shalin led research and programs at the Association of Public and Land-grant Universities (APLU), held policy positions at the American Academy of Arts and Sciences and the University of Michigan, as well as consulting roles with the AAAS, the Alfred P. Sloan Foundation, and the International Monetary Fund. Shalin is a graduate of the University of Georgia, the birthplace of American public higher education. Connect with Shalin on Twitter at @ShalinJyotishi @NewAmericaEd. 